\title{
EVALUATING THE STRUCTURAL INTEGRITY OF THE SAINT ANTONIO BARREL VAULT IN THE FORTRESS OF ALMEIDA BY COMBINING LASER SCANNER AND LIMIT ANALYSIS
}

\author{
L.J. Sanchez-Aparicio ${ }^{1, *}$, P. Rodriguez-Gonzalvez ${ }^{1,2}$, D. Gonzalez-Aguilera ${ }^{1}$, Luís F. Ramos ${ }^{3}$ \\ ${ }^{1}$ Department of Cartographic and Land Engineering. University of Salamanca, High Polytecnic School of Ávila, Ávila, Spain - \\ (luisj, pablorgsf, daguilera) @usal.es \\ ${ }^{2}$ Department of Mining Technology, Topography and Structures, Universidad de León, Ponferrada, Spain p.rodriguez@unileon.es \\ ${ }^{3}$ ISISE, Department of Civil Engineering, University of Minho, Guimarães, Portugal lramos@civil.uminho.pt
}

\section{Commission II}

KEY WORDS: Historical construction, Trace Italienne fortress, Masonry, Laser scanner, Structural diagnosis, Limit Analysis

\begin{abstract}
:
Under the framework of the modern theory of restoration, this paper shows the experimental results obtained during the structural diagnosis of one of the most important master gates inside the military modern complex of Almeida in Portugal: the inner master gate of Saint Antonio. This master gate was conceived with the aim of supporting the siege of an early modern army, using to this end a masonry framework filled by a natural soil able to absorb the impacts. However, this infill is promoting the disaggregation of the masonry and thus the reduction of its bearing capacity. In order to evaluate the current and future structural behaviour, it is proposed a method able to combine the terrestrial laser scanner with the limit analysis for masonry constructions. The results obtained by this combination shows that the major barrel vault has, in its current conservation state, enough bearing capacity to support an agglomeration of people. However, it is recommended a material restitution in order to recover the contact are between masonry blocks as well as to recover the architectural interpretation of the element.
\end{abstract}

\section{INTRODUCTION}

Modern restoration principles, founded on the precepts exposed by the International Charter of Krakow (Charter of Krakow, 2000), understand the conservation and restoration of historical constructions as a critical process. This process has the goal of recovering its intrinsic values for which is necessary a scientific and rigorous diagnostic. Within this context, the analysis of the structural stability of these constructions has been placed as a critical step in order to understand their current bearing capacity as well as the origin of the damages presented (Bautista-De Castro et al., 2018; Sánchez-Aparicio et al., 2016). This knowledge allows to design proper restoration actions based on a minimum intervention philosophy (ICOMOS, 2005).

Under this basis, this article shows the results obtained during the structural assessment of the Saint Antonio major barrel vault inside the modern military complex of Almeida in Portugal. This example of Trace Italienne fort, made up by a total of six bastions and six master gates (Figure 1a) was erected between the $\mathrm{XV}^{\text {th }}$ and the $\mathrm{XVI}^{\text {th }}$ centuries to defend the Portuguese border during the Restoration Wars (Cobos and de Sousa Campos, 2013). However, the constructive disposition of its master gates, mainly composed by a natural infill encapsulated within a masonry framework (Figure 1b), is fostering the degradation of the masonry. This degradation is especially eminent in the major barrel vault of the Saint Antonio inner master gate, requiring a structural evaluation of its bearing capacity in order to know the safety conditions against the major tourist event that take place each year: the recreation of the French siege (Arce et al., 2017).

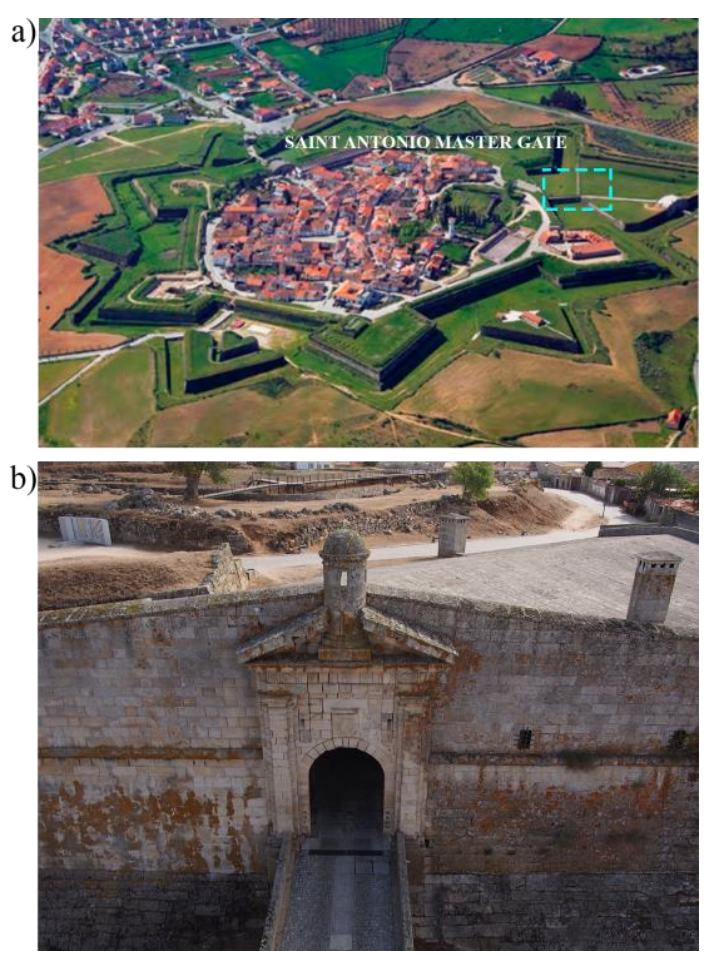

Figure 1. Almeida fortress: a) general view of the fortress and location of the Saint Antonio inner master gate; and b) aerial view of the main façade of the Saint Antonio master gate.

* Corresponding author. E-mail address: luisj@ usal.es (L.J. Sanchez-Aparicio). 
Within this context, this paper is structured as follows: after this initial introduction; Section 2 presents the diagnosis carried out on the major barrel vault; Section 3 exposes the results of the limit analysis; Section 4 evaluates the future structural performance of the barrel vault; and finally, Section 5 outlines the main conclusions.

\section{DIAGNOSIS OF THE MAJOR BARREL VAULT}

\subsection{Constructive description}

Located in the west side of the Almeida fortress (Figure 1a), the inner master gate of Saint Antonio is made up by two façades. These façades were erected with regular ochre granite masonry blocks (Figure 1b), being communicated by a barrel vault with non-linear trace (Figure 2). This major barrel vault has a total span of $6.8 \mathrm{~m}$ and a rise/span ratio of 0.5 . At both sides of this barrel vault the gate shows two minor barrel vaults that served as spaces of vigilance (Figure 2). On the top part, this master gate is covered by a gable roof made up by regular grey granite slabs (Figure 1b).

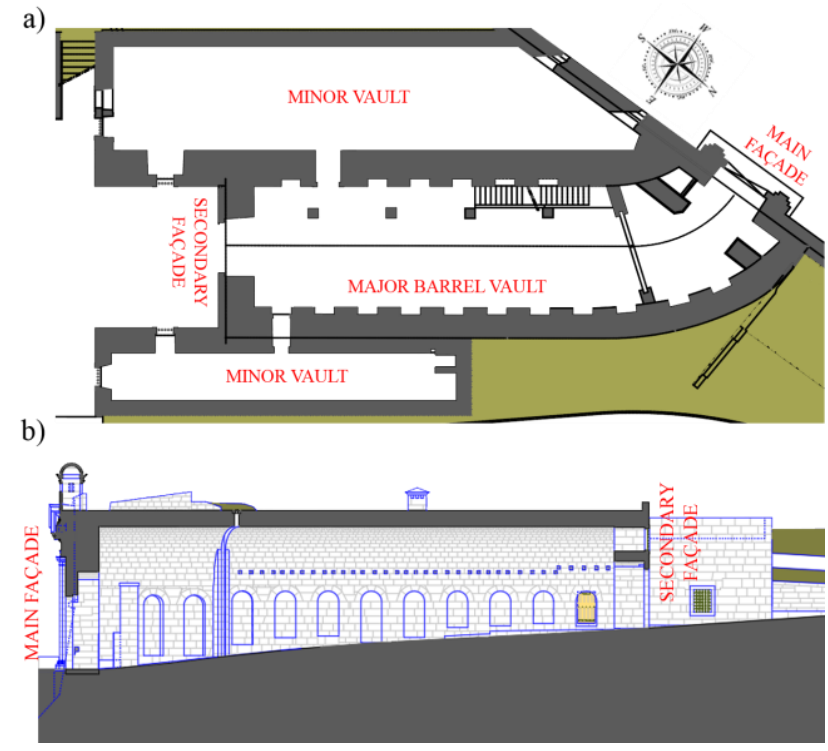

Figure 2. Constructive disposition of the inner master gate: a) plant view and $b$ ) longitudinal section along the trace of the major barrel vault.

\subsection{Visual indicators of damage presented in the major barrel vault}

Previously to the structural analysis of the major barrel vault, a visual inspection was carried out with the aim of detecting the most important indicators of damage presented on this constructive element as well as the degradation mechanisms (Figure 3).

Result of this visual inspection it was possible to detect the following indicators of damage (HeritageCARE, 2017) (Figure 3): (i) moisture; (ii) salt crusts; (iii) green algae; (iv) material loses; (v) disaggregation; and (vi) soiling. Between this wide variety of damages, and from a structural point of view, highlights the intense material loses along the entire barrel vault. As exposed Sánchez-Aparicio et al. (Sánchez-Aparicio et al., 2018) in their study about the conservation state of the San Francisco inner master gate, it is probably that this material loses are promoted by the hydration-dehydration cycles of the melting salts presented in the infill.

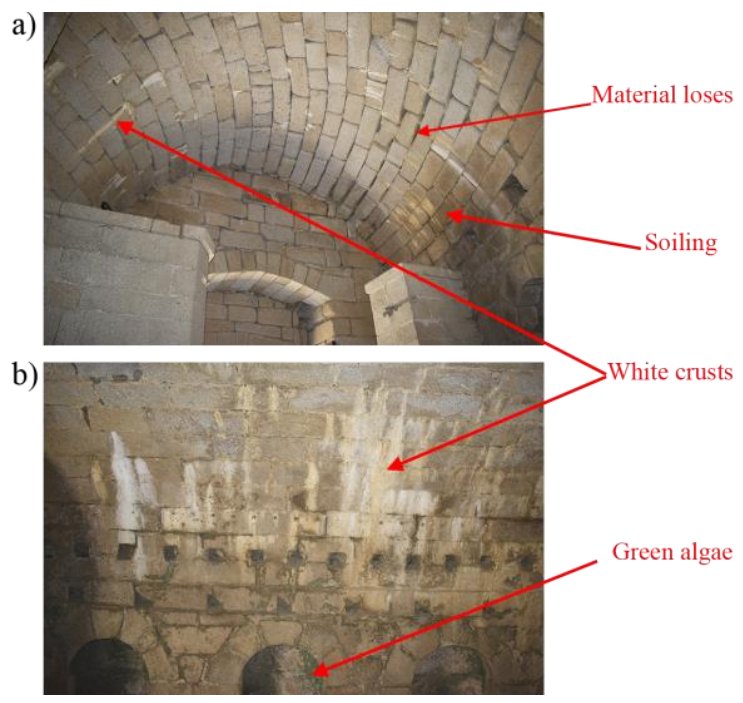

Figure 3. Photos taken during the visual inspection carried out in the master gate: a) image of the main entrance; and b) detailed image of the south support of the major barrel vault.

\subsection{Digitalization by means of the terrestrial laser scanning technology}

According with the results provided by the visual inspection, the next step required for the structural evaluation of the barrel vault was its $3 \mathrm{D}$ digitalization. The unfavourable illumination conditions of the barrel vault, as well as the necessity of capturing all the geometrical features of this constructive element placed the terrestrial laser scanner (TLS) as the best solution. For the present study case, the laser scanner Faro Focus $120^{\circledR}$ was used to digitalize the construction. This laser scanner, based on the Amplitude Modulated Continuous Wave (AMCW) phase-based principle, highlights for its portability and fast data acquisition, allowing a capture rate comprised between 122,000 and 976,000 points per second.

Additionally to the TLS system, several registration spheres with $14.5 \mathrm{~cm}$ of diameter were used to compute a rough alignment of the scan stations. Then, this alignment was refined through the use of the Iterative Closest Point algorithm (Besl and McKay, 1992). As a result, it was needed a total of six scan stations to capture the whole major barrel vault. This amount of scan stations was motivated by the needed of capturing all the geometrical features (specially the material losses) presented on the barrel vault.

Taking into consideration the main aim of the present study, the structural diagnosis of the vault, a curvature-based filter was applied on the registered point cloud, decimating flat areas to 1 $\mathrm{cm}$ of density. This filter allowed to reduce the amount of data captured from $114,085,835$ points to $4,952,783$ points, maintaining all the geometrical details (Figure 4). 


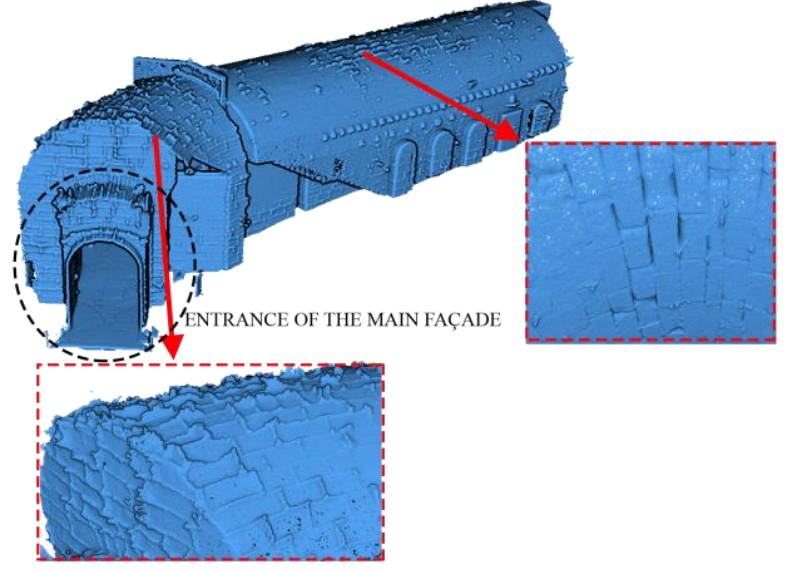

Figure 4. General view of the point cloud obtained during the present experimental campaign. The red squares show a

detailed view of the point cloud on which is possible to observe all the geometrical features captured by the TLS.

\subsection{Analysis of the point cloud to assess its structural conditions}

In order to assess the current structural condition of the major barrel vault, several sections were extracted in three different areas of the barrel vault (Figure 5).

a)

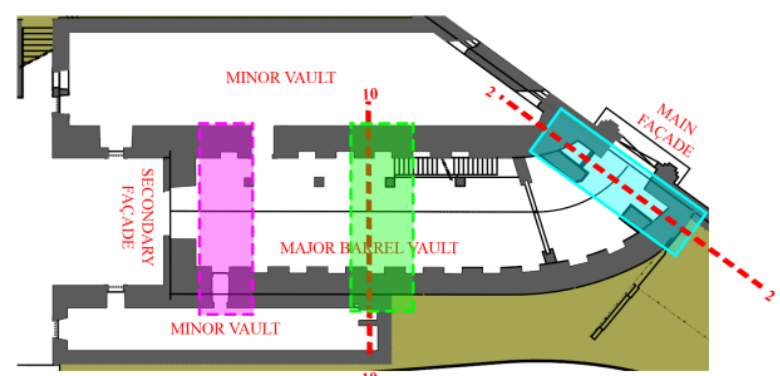

b)
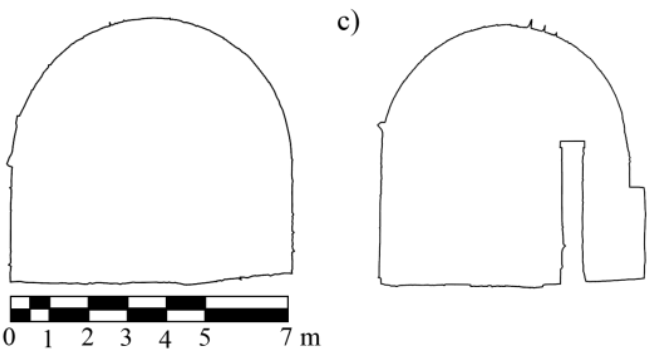

Figure 5. Areas evaluated during the structural diagnosis: a) plant view, b) example of one section extracted from the magenta area; and c) example of one section extracted from the green area.

From the extracted sections it was possible to draw the first conclusions about the current state of the vault. The supports in the whole section shown a slight inclination (Figure 6), probably experimented in the initial load-state of the structure (after the removal of the centring). This geometrical disposition suggests that the dimensions of the supports within the passive pressure of the infill are enough to counteract the trust generated by the vault (Figure 5).

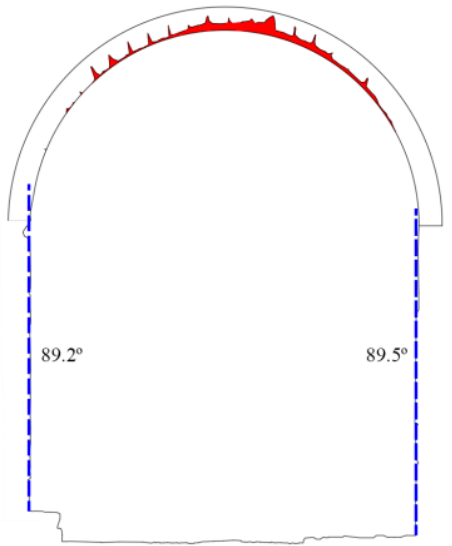

Figure 6. Results obtained during the evaluation of the supports in section 2 .

With respect to the barrel vault it was not possible to detect deformations, indicating that the vault has found a compression solution on which the trust line does not touch the geometrical limits of the section. However, this constructive element, especially in the entrance of the master gate (blue area in Figure 5), shows important material loses that reduce its resistance section. In this area the current section is the $90 \%$ of the initial one. This value is lower than the value found for the magenta and green sections (around $94 \%$ ).

In contrast with the values found for the resistance section, it was possible to observe many areas on which the material losses are eminent (see the keystone in Figure 7a). These areas are hindering the capacity of the vault to find a status on which the trust line can be drawn within its geometrical limits (equilibrium solution), as well as fostering the concentration of compression stresses which could arise in resistance problems.

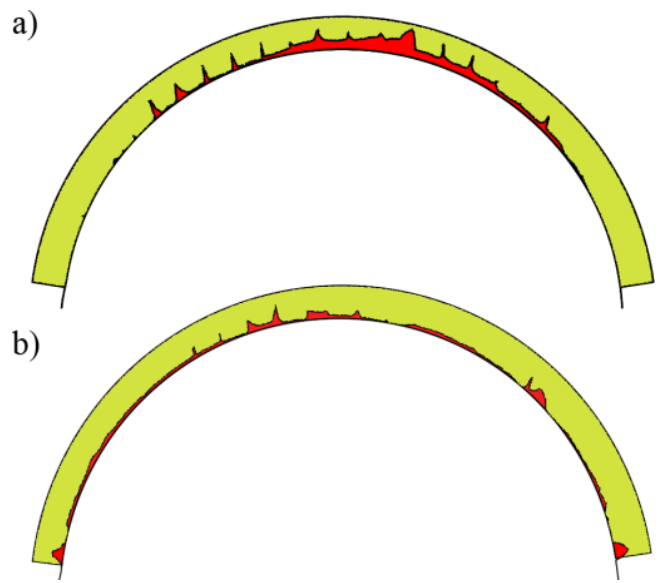

Figure 7. Detail of the sections considered for the numerical simulation: a) section 2; and b) section 10 . In light green the current section, and in red the estimated material loses.

\section{LIMIT ANALYSIS OF ITS CURRENT CONDITIONS}

Understanding the barrel vault as a succession of arches along its trace, its stability can be explained by means of the stability of each arch (Heyman, 1966; Huerta Fernández, 2001). Among 
the different variety of numerical methods able to evaluate the structural capacity of masonry archers, from the equilibrium approach proposed by Heyman (Heyman, 1966), to the finite element method (Arce et al., 2017; Conde et al., 2017), the limit analysis of historical construction has been placed as an attractive method (Conde et al., 2017). This computational approach highlights for its simplicity, requiring a low number of inputs to solve problem (Lourenço, 2013).

On this basis, the bearing capacity of the major barrel vault was evaluated by means of the rigid block method proposed by Gilbert (Gilbert and Melbourne, 1994) along the different characteristic archers of the vault (Figure 5). This computational strategy, initially proposed by Livesley (Livesley, 1978), considers the masonry as an assemblage of independent and infinitely rigid blocks connected with zero tensile strength joints on which is possible to simulate different mechanical phenomena such as the failure by compression (crushing phenomenon) or the sliding of the blocks. Within this context, the method maximizes the security load factor using a linear programming formulation and the lower bound theorem (Livesley, 1978).

Regarding the infill, the limit analysis used considered the following effects: i) the pre-stresses effect on the masonry due to the infill's weight; ii) the capacity of dispersing live loads; and the passive restraint effect.

\subsection{Numerical model}

On the basis of the limit analysis previously defined, two numerical models were created from the laser scanner sections extracted along the trace of the major barrel vault (Figure 5). On the one hand, a numerical model of one section was generated coming from the entrance of the main façade (more precisely the section 2) (Figure 7a). This area is relevant due to the intensive material loses presented in the major barrel vault, as well as the low contribution of the minor barrel vault (Figure 2). On the other hand, the other section evaluated was a section placed at the middle of the barrel vault: the section 10 (Figure 7b). In general, this section has less material loses than the section of the entrance, however it shows a concentration of material losses in the area near the keystone. Additionally, this section has the contribution of the two minor barrel vaults (Figure 5).

For both numerical models the following assumptions were considered: (i) a load-combination made up by the self-weight of the structure and a distributed load of $5 \mathrm{kN} / \mathrm{m}^{2}$ (European Standard, 2004), which represents the annual event that take place on the master gate: the representation of the 1810 battle; (ii) a density of $2,100 \mathrm{~kg} / \mathrm{m}^{3}$ for the masonry and $1,900 \mathrm{~kg} / \mathrm{m}^{3}$ for the infill; (iii) a compression strength of $2.4 \mathrm{MPa}$ for the masonry according with the values obtained by (Arce et al., 2017) in the inner master gate of Saint Francisco; (iv) a friction coefficient between blocks of 0.6 ; and (v) a frictional cohesive infill with a cohesion value of $20 \mathrm{kPa}$ and a friction angle of $30^{\circ}$ (Conde et al., 2017). Additionally to this considerations, both numerical models included an accurate definition of the masonry joints, since the material loses are mainly concreated in these areas (Figure 7). To this end the contact between rigid blocks were reduced (Figure 8). It is worth mentioning that the roof covering and the supports were modelled according with the data provided by the last restoration project. Also, the supports in contact with the soil were not modelled explicitly since its section is enough to ensure low compressions stresses as well as the active pressure of the soil is enough to ensure the equilibrium of the support in all situations.

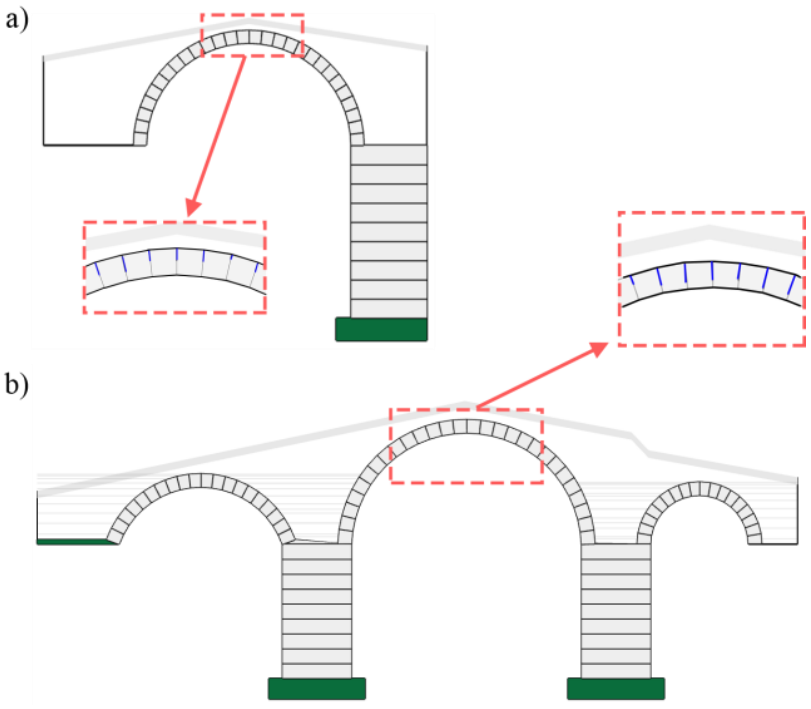

Figure 8. Numerical models considered for the structural assessment of the major barrel vault: a) numerical model for section 2; and b) numerical model for section 10 . In blue the current contact section.

\subsection{Numerical results}

In its current state of conservation both sections, and thus the barrel vault, showed enough bearing capacity to support a possible agglomeration of people (Table 1). This capacity is mainly limited by the compression strength of the masonry (equilibrium + crushing), showing an average safety factor of 6.0. In case of not considering the effect of crushing (equilibrium solution), the capacity of the barrel vault grows ups to a safety factor of 11.2 (Table 1).

\begin{tabular}{|l|c|c|}
\hline Section & \multicolumn{2}{|c|}{ Safety factor } \\
\hline \multirow{2}{*}{2} & Equilibrium & Equilibrium + crushing \\
10 & $12.0(46.7)$ & $6.3(14.4)$ \\
\cline { 1 - 3 } & $10.1(33.3)$ & $5.5(10.0)$ \\
\hline
\end{tabular}

Table 1. Results of the limit analysis carried out on the most damage sections of the barrel vault. Between brackets the safety factor of the initial configuration (without material loses).

Regarding the topology of the collapse mechanism, both sections shown an asymmetric topology (Figure 9). This asymmetry is promoted by the different material losses presented along the arch's trace. On the one hand, the collapse mechanism of section 2 takes place on the keystone, on $2 / 3$ of the span and on the right springer (Figure 9a). On the other hand, the collapse mechanism of the section 10 takes place in the major barrel vault on the key stone, at mid-span and at on right springer (Figure 9b). 
a)

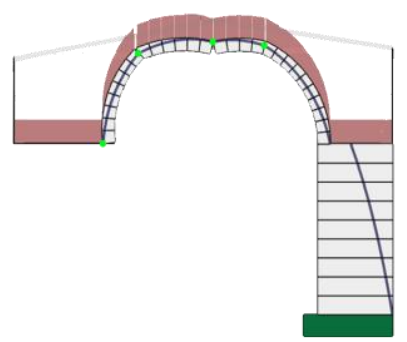

b)

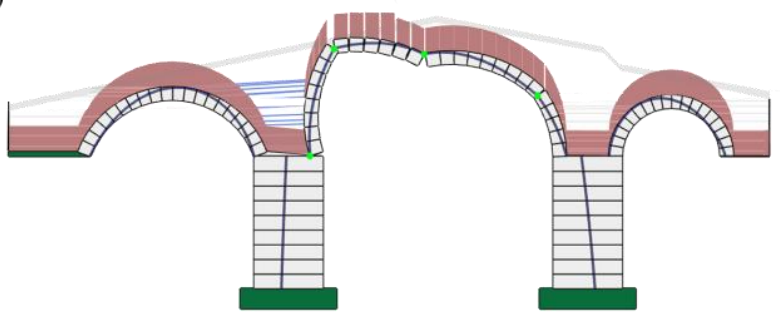

Figure 9. Collapse mechanism: a) section 2; and b) section 10. In dark blue the trust line; in light green the points on which the hinges appear, and in brown the load distribution.

\section{STRUCTURAL ASSESSMENT IN CASE OF CONTINUING THE MATERIAL LOOSES}

The geometrical and constructive disposition of the inner master gate, with a low gravity centre and the presence of an infill that can absorb part of horizontal actions that take place during a seismic event within the area on which is located the fortress (zone 1.6 according with the National Portuguese Annex) (European Standard, 1998), place the seismic performance of this construction in a second plane. Taking this into consideration, the main hazard of this construction are the material losses.

On this basis, it was carried out several predictive evaluations in order to know the evolution of the bearing capacity of the barrel vault in case of continuing the material loses. This material loses were simulated reducing the contact section between blocks in a specific percentage with respect to the initial ones. During these evaluations, several situations were considered in order to improve the knowledge about the evolution of the bearing capacity of the barrel vault: (i) a limit analysis based on equilibrium conditions without considering a possible failure by compression; and (ii) a limit analysis with possibility of having crushing problems.

Figure 10 shows the results obtained by the predictive structural analysis on the sections considered. As expected, if the damage continues, the safety factor of the barrel vault will decrease, appearing compression failures due to the reduction of the contact area. For a level of damages up to the $30 \%$ of the current ones, the safety factor of the barrel vault will be lower than 2 (Figure 10), being this limit the geometrical safety factor recommended by Heyman for arches (Heyman, 1966). In case of having approximately the $40 \%$ of the current damages, the barrel vault will suffer local problems in presence of an agglomeration of people. It is worth mentioning that the compression strength reduces, approximately, the $50 \%$ of the structural capacity of the sections evaluated (equilibrium solution) (Figure 10).

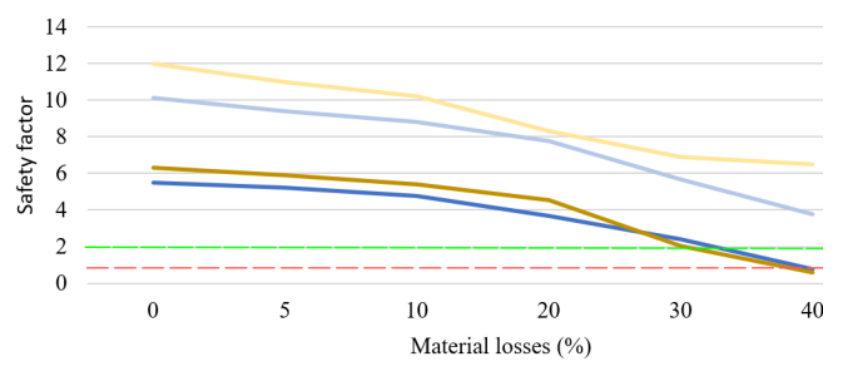

$\begin{array}{ll}- \text { Section } 20 \text { (Equilibrium + Crushing) } & \text { Section } 20 \text { (Equilibrium) } \\ - \text { Seccion } 2 \text { (Equilibrium + Crushing) } & \text { Seccion } 2 \text { (Equilibrium) }\end{array}$

Figure 10. Evolution of the safety factor. In green the recommended safety factor for arches; and in dashed red the collapse situation.

Regarding the topology of the collapse mechanisms, it was possible to observe a quasi-symmetric collapse mechanism in section 2 and an asymmetric collapse mechanism in section 10 (Figure 10). On the one hand the plastic hinges in section 2 take place at the keystone, at the 2/3 span and at both springers. On the other hand, section 10 collapse by the formation of four plastic hinges in the major barrel vault: i) two near the keystone, ii) one at the mid-span; and (iii) another at the right springer. The new topology of the collapse mechanisms could be attributed to the formation of new crushing areas (Figure 9) (Figure 11).

a)

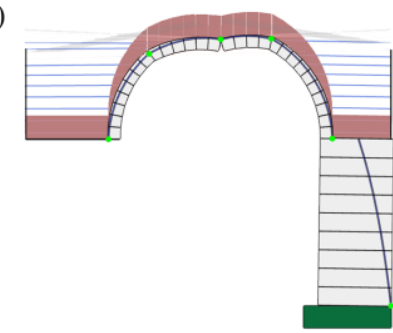

b)

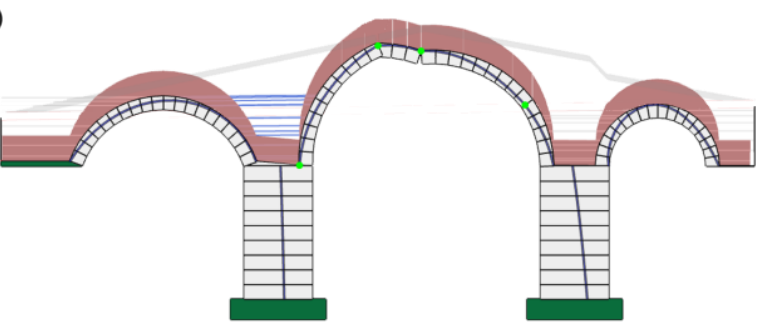

Figure 11. Collapse mechanism at $40 \%$ of damage: a) section 2; and b) section 10. In dark blue the trust line; in light green the points on which the hinges appear, and in brown the load distribution.

\section{CONCLUSIONS}

This paper shown the result obtained during the structural evaluation of the major barrel vault of the inner master gate of Saint Antonio. To this end, the terrestrial laser scanner technique and the limit analysis approach were combined. In spite of the material loses show along its trace, the major barrel vault shows enough bearing capacity even for the most unfavourable event: the representation of the 1810 battle. 
However, if the material losses continue, the bearing capacity of the barrel vault will decrease, being recommended the restitution of the joints between blocks in order to recover the architectural continuity of the vault and its bearing capacity.

Further investigations will be focused on the use of additional sensors such as the ground penetrating radar, the sonic tests and the impact-echo method in order to improve the geometrical knowledge of this structural system. Additionally, it will be evaluated the structural stability of the vault by means of the finite element method. This numerical strategy will allow to analyse the evolution of the different crushing areas, the role of the infill in the structural stability of the system as well as the evaluation of the structural capacity at different casuistic (slight movement of the supports or settlements among others).

\section{AKNOWLEDGEMENTS}

This work was financed by ERDF funds through the V SUDOE INTERREG program within the framework of the HeritageCARE project, Ref. SOE1/P5/P0258. This research has been also partially supported by Patrimonio 5.0 funded by Junta of Castilla y León, Ref. SA075P17.

\section{REFERENCES}

Arce, A., Ramos, L.F., Fernandes, F.M., Sánchez-Aparicio, L.J., Lourenço, P.B., 2017. Integrated structural safety analysis of San Francisco Master Gate in the Fortress of Almeida. International Journal of Architectural Heritage, 1-18.

Bautista-De Castro, Á., Sánchez-Aparicio, L.J., Ramos, L.F., Sena-Cruz, J., González-Aguilera, D., 2018. Integrating geomatic approaches, Operational Modal Analysis, advanced numerical and updating methods to evaluate the current safety conditions of the historical Bôco Bridge. Construction and Building Materials 158, 961-984.

Besl, P.J., McKay, N.D., 1992. A method for registration of 3-D shapes. IEEE Transactions on pattern analysis and machine intelligence 14, 239-256.

Charter of Krakow, 2000. Principles for conservation and restoration of built heritage. Marsilio, Venice.

Cobos, F., de Sousa Campos, J.d.S., 2013. Almeida, Ciudad Rodrigo: la fortificación de la Raya Central. Consorcio Transfronterizo de Ciudades Amuralladas.

Conde, B., Ramos, L.F., Oliveira, D.V., Riveiro, B., Solla, M., 2017. Structural assessment of masonry arch bridges by combination of non-destructive testing techniques and threedimensional numerical modelling: Application to Vilanova bridge. Engineering Structures 148, 621-638.

European Standard, 1998. 1 (2010) Eurocode 8: Design of structures for earthquake resistance. Part 1: General rules, seismic actions and rules for buildings.

European Standard, 2004. Eurocode 1: Actions on Structures. Part 1-1. General Actions; Densities, Self-weight, Imposed Loads for Buildings. BSI.

Gilbert, M., Melbourne, C., 1994. Rigid-block analysis of masonry structures. Structural engineer 72 .
HeritageCARE, 2017. Survey of construction systems, type of damages and deterioration processes within the SUDOE territory, HeritageCARE project, http://heritagecare.eu/wpcontent/uploads/2017/09/HeritageCARE-Report-1.1.pdf (4 September 2018).

Heyman, J., 1966. The stone skeleton. International Journal of solids and structures 2, 249-279.

Huerta Fernández, S., 2001. Mechanics of masonry vaults: The equilibrium approach.

ICOMOS, 2005. Recommendations for the analysis, conservation and structural restoration of architectural heritage. https://www.icomos.org (4 September 2018).

Livesley, R., 1978. Limit analysis of structures formed from rigid blocks. International Journal for Numerical Methods in Engineering 12, 1853-1871.

Lourenço, P.B., 2013. Computational strategies for masonry structures: multi-scale modeling, dynamics, engineering applications and other challenges, Congreso de Métodos Numéricos en Ingeniería. Semni, pp. 1-17.

Sánchez-Aparicio, L.J., Del Pozo, S., Ramos, L.F., Arce, A., Fernandes, F.M., 2018. Heritage site preservation with combined radiometric and geometric analysis of TLS data. Automation in Construction 85, 24-39.

Sánchez-Aparicio, L.J., Villarino, A., García-Gago, J., González-Aguilera, D., 2016. Photogrammetric, Geometrical, and Numerical Strategies to Evaluate Initial and Current Conditions in Historical Constructions: A Test Case in the Church of San Lorenzo (Zamora, Spain). Remote Sensing 8, 60. 